\title{
Knowledge, attitudes and practices of pharmacists about pharmacovigilance, Libya
}

\author{
Ahmed Atia, ${ }^{1}$ Amal Botto ${ }^{2}$ and Safia Alarbi ${ }^{2}$
}

${ }^{1}$ Department of Anaesthesia and Intensive Care, Faculty of Medical Technology, University of Tripoli, Tripoli, Libya. ${ }^{2}$ Department of Pharmacy, Almharat College of Medical Sciences, Janzur, Libya. (Correspondence to: Ahmed Atia: ah.atia@uot.edu.ly).

\begin{abstract}
Background: The concept of pharmacovigilance is not well known in Libya and its practice is still in the early stages. Aims: This study aimed to determine the knowledge, attitudes and practices of pharmacists in Tripoli, Libya about pharmacovigilance and the reporting of adverse drug reactions.

Methods: A cross-sectional study was conducted from October 2019 to February 2020 of working pharmacists randomly selected from pharmacies in Tripoli. Participants were eligible for inclusion if they had a degree or diploma in pharmacy from a recognized university or institute. Data were collected using a validated self-administered questionnaire.

Results: Of 500 pharmacists selected, 408 completed the questionnaire. The pharmacists' knowledge of pharmacovigilance and reporting of adverse drug reactions was poor overall: only $28.9 \%$ correctly defined pharmacovigilance and $14.7 \%$ knew about the existence of a centre for pharmacovigilance in Libya. The attitudes of the pharmacists to pharmacovigilance was positive: $77.2 \%$ believed that pharmacovigilance needed to be included in the pharmacy curriculum and $73.0 \%$ said that they would practice pharmacovigilance if trained. Pharmacists depended mostly on drug information leaflets to update their knowledge on adverse drug reactions.
\end{abstract}

Conclusion: Given the pharmacists' low level of knowledge about pharmacovigilance but their readiness to become involved if trained, training programmes should be introduced for practising pharmacists to improve their knowledge and encourage their active participation in pharmacovigilance. Regulators need to reinforce the importance of reporting adverse drug reactions and implement pharmacovigilance policies in the Libyan health care system.

Keywords: pharmacovigilance, adverse drug reactions, pharmacists, knowledge and attitudes, Libya

Citation: Atia A; Botto A; Alarbi S. Knowledge, attitudes and practices of pharmacists about pharmacovigilance, Libya. East Mediterr Health J. 2021;27(7):693-697. https://doi.org/10.26719/2021.27.7.693

Received: 20/05/20; accepted: 12/10/20

Copyright $@$ @ World Health Organization (WHO) 2021. Open Access. Some rights reserved. This work is available under the CC BY-NC-SA 3.0 IGO license (https://creativecommons.org/licenses/by-nc-sa/3.0/igo).

\section{Introduction}

Pharmacovigilance, as defined by the World Health Organization (WHO), is the "science and activities relating to the detection, assessment, understanding and prevention of adverse effects or any other medicine-related problem" (1). WHO defined an adverse drug reaction as "a response to a medicine which is noxious and unintended, and which occurs at doses normally used in man..." (2). Data from several studies have shown that adverse drug reactions were linked to $6.5 \%$ of extended hospitalizations and they are considered an important cause of death in the United Kingdom of Great Britain and Northern Ireland (3). The influence of health care specialists with regard to adverse drug reactions is substantial and has encouraged ongoing ascertainment of the benefitrisk percentage of some drugs (4). Several approaches have been implemented to detect adverse drug reactions, such as spontaneous reporting which relies on health care professionals detecting and taking the initiative to report an adverse drug reaction. This approach is considered an effective method that has contributed to greater pharmacovigilance in many countries (5).
One of the challenges of reporting adverse drug reactions is to build a culture of reporting among the health care personnel, particularly among the pharmacists, as they are more involved with patient care. Currently, reporting of adverse drug reactions in Libya is low mainly because of lack of awareness, training, and time limitations, and Libyan community pharmacists limit their role to simply dispensing marketed preparations $(6,7)$. Few studies in Libya have been published on the reporting of adverse drug reactions by prescribers and health care professionals (8). Therefore, we aimed to evaluate the knowledge, attitudes and practices of working Libyan pharmacists about pharmacovigilance and reporting of adverse drug reactions.

\section{Methods}

\section{Study design, setting and sample}

This was a descriptive cross-sectional study of a randomly selected sample of registered pharmacists in Tripoli. Participants were eligible for inclusion in this survey if they had graduated with a degree in pharmacy from a recognized university, and gave their consent to partici- 
pate in the study. Pharmacy assistants without a pharmacy degree were excluded.

Sample size was calculated using a $5 \%$ margin of error and $95 \%$ confidence level, giving a sample size of 500 $(9,10)$.

\section{Data collection}

We conducted a survey study during October 2019 to February 2020 using a prevalidated questionnaire. The questionnaire was validated on a sample of three specialists in the field of clinical pharmacy at the University of Tripoli, and their comments were taken into consideration to revise the questionnaire.

Participants were informed about the objectives of the survey in a letter attached to the questionnaire, which we delivered and collected by hand.

The questionnaire included information on demographic characteristics of the pharmacists and 18 survey items organized into two sections: 13 knowledge questions and 5 attitude questions. While yes/no questions tested the practice of adverse drug reactions reporting among the participants.

For knowledge, a score of $\geq 9$ out of 13 questions was considered good knowledge, and for attitude, a score of $\leq 3$ was considered poor. A yes answer was scored $1, a$ no answer was scored zero. We also asked pharmacists about their primary source of information to update their knowledge on adverse drug reactions.

\section{Statistical analysis}

Results are reported as frequencies and percentages.

\section{Ethical considerations}

This study was approved by the ethical committee of the Department of Anaesthesia and Intensive Care, Faculty of Medical Technology, University of Tripoli, Libya (Ref No. 1102/2020).

\section{Results}

The questionnaire was distributed to 500 pharmacists, 408 of whom returned the completed questionnaire (81.6\% response rate). As shown in Table 1, just over half the respondents (54.9\%) were women and were 20-30 years in age. About three quarters of the pharmacists (74.5\%) had a bachelor degree and $59.8 \%$ had $1-10$ years of work experience.

Knowledge of and attitude to reporting adverse drug reactions and pharmacovigilance were generally low (Table 2). For only one knowledge questions did more than $50 \%$ of the pharmacists know the correct response: female patients should be asked if they are pregnant when dispensing medications to them (71.3\%). Only $28.9 \%$ of respondents correctly defined pharmacovigilance and $14.7 \%$ knew that there is a centre for pharmacovigilance in Libya. As regards adverse drug reactions, only $46.1 \%$ of the respondents correctly defined adverse drug reactions and $14.7 \%$ knew how to report such reactions. However, only $8.8 \%$ had actually reported an adverse drug reactions.
As regards attitude to pharmacovigilance, 38.7\% thought that not enough importance is given to pharmacovigilance in the pharmacy curriculum and $40.2 \%$ thought that it is a responsibility of pharmacists to report adverse drug reactions. However, only $45.6 \%$ of the pharmacist thought that information on how to report adverse drug reactions should be taught to undergraduate pharmacy students. Finally, for the question on serious adverse drug reactions being known before a medicine is marketed, $41.1 \%$ of the respondents answered correctly and $28.4 \%$ knew that the reason for not reporting a suspected adverse drug reaction was due to the uncertainty of its association with the drug.

Regarding the results of pharmacovigilance attitudebased questions, the overall correct answers were good: $57.8 \%$ of pharmacists believed that reporting adverse drug reactions was an essential role of pharmacists and $77.2 \%$ thought that pharmacovigilance should to be included in the pharmacy curriculum and 90.0\% believed that reporting adverse drug reactions must be made compulsory. As regards applying pharmacovigilance themselves, $73 \%$ said that they would practice pharmacovigilance if trained.

As shown in Figure 1, the pharmacists mainly relied on drug information leaflets to update their knowledge on adverse drug reactions (42.2\%). Other sources included reference and text books (20.6\%) and the internet (14.2\%).

\section{Discussion}

To the best of our knowledge, this is the first study to explore the knowledge, attitudes and practices of Libyan

\begin{tabular}{lc}
\hline $\begin{array}{l}\text { Table } 1 \text { Demographic characteristics of the pharmacists, } \\
\text { Tripoli, Libya }\end{array}$ & No. $(\%)(\mathbf{n}=408)$ \\
\hline Variable & $184(45.1)$ \\
\hline Sex & $224(54.9)$ \\
\hline Male & \\
Female & $230(56.4)$ \\
Age (years) & $152(37.3)$ \\
\hline $20-30$ & $26(6.4)$ \\
$31-40$ & \\
$41-50$ & $54(13.2)$ \\
Qualification & $304(74.5)$ \\
\hline Institute diploma & $50(12.3)$ \\
Bachelor degree & \\
Postgraduate degree & $72(17.6)$ \\
Experience (years) & $160(39.2)$ \\
\hline$<1$ & $84(20.6)$ \\
$1-5$ & $92(22.5)$ \\
$6-10$ & \\
$>10$ &
\end{tabular}




\begin{tabular}{|c|c|}
\hline Items & No. (\%) \\
\hline Knowledge of pharmacists of pharmacovigilance & Correct answer \\
\hline 1. Do you know what pharmacovigilance is? & $118(28.9)$ \\
\hline 2. I know that there is a centre of pharmacovigilance in Libya. & $60(14.7)$ \\
\hline 3. I know about adverse drug reactions. & $188(46.1)$ \\
\hline 4. I know how to report adverse drug reactions to the relevant authorities in Libya. & $60(14.7)$ \\
\hline 5. Do you know that a responsibility of pharmacists is to report adverse drug reactions? & $164(40.2)$ \\
\hline 6. Pharmacists are usually the first point of contact for people to report an adverse drug reaction. & $243(59.6)$ \\
\hline 7. Patient should be advised about adverse drug reactions every time their medications are dispensed. & $182(44.6)$ \\
\hline 8. Female patients should be asked if they are pregnant when dispensing medications to them. & $291(71.3)$ \\
\hline 9. Pharmacy students should be taught how to report adverse drug reactions. & $186(45.6)$ \\
\hline 10. All serious adverse drug reactions are known before a medicine is marketed. & $168(41.2)$ \\
\hline $\begin{array}{l}\text { 11. Reason for a pharmacist not reporting a suspected adverse drug reaction is due to the uncertainty of its } \\
\text { association with the drug. }\end{array}$ & $116(28.4)$ \\
\hline Attitude of pharmacists to pharmacovigilance & Positive attitude \\
\hline 12. Reporting adverse drug reactions is an essential role of the pharmacist. & $236(57.8)$ \\
\hline 13. Pharmacovigilance needs to be included in pharmacy curriculum. & $315(77.2)$ \\
\hline 14. Reporting adverse drug reaction must be made compulsory. & $367(90.0)$ \\
\hline 15. I would practice pharmacovigilance if trained. & $298(73.0)$ \\
\hline 16. Have you ever reported an adverse drug reaction? & $36(8.8)$ \\
\hline 17. Do you think too little importance has been given to pharmacovigilance in the pharmacy curriculum? & $158(38.7)$ \\
\hline $\begin{array}{l}\text { 18. With my present knowledge, I am well prepared to report any apparent adverse drug reaction in my future } \\
\text { practice. }\end{array}$ & $240(58.8)$ \\
\hline
\end{tabular}

pharmacists about pharmacovigilance and adverse drug reactions.

Overall, the attitude of the pharmacists was better than their knowledge. This is not surprising as pharmacy students in Libya are not adequately exposed to pharmacovigilance in their curricula. Moreover, pharmacy students have received more training on detection, understanding and prevention of adverse drug reactions in their syllabus.

Overall, the knowledge of reporting adverse drug reactions and pharmacovigilance was low. Our results are in agreement with studies conducted in Saudi Arabia and Sudan (11,12). However, our results differ from those of studies conducted in Jordan, Kuwait, Lebanon and Qatar where higher levels of knowledge on pharmacovigilance were reported (13-16).

The concept of pharmacovigilance and the presence of a pharmacovigilance centre in Libya were not well known. This finding supports the suggestion that the Libyan pharmacovigilance system is still in its infancy, and governmental authorities may treat these systems as a low priority with insufficient specialists and financial resources (6).

Most of the participants thought that reporting of adverse drug reactions should be made compulsory and that pharmacovigilance needs to be included in curriculum. Our results are in agreement with earlier surveys that identified reporting of adverse drug reactions as a professional obligation that requires ethical commitment by health care professionals $(11,17)$.
About $57.8 \%$ of the pharmacists in our study agreed that reporting adverse drug reactions was an essential role of all practising pharmacists. Comparable results have been reported in other research (12).

Pharmacists in our study mostly depended on drug information leaflets to update their knowledge on adverse drug reactions and on textbooks to a lesser extent. Only $14.2 \%$ used the internet as their primary source of information although reputable websites for drug-related information are available. Awareness needs to be raised among pharmacists about such websites and their usefulness for obtaining up-to-date information on drugs and adverse drug reactions.

\section{Figure 1 Pharmacists' main source of information on adverse} drug reactions, Tripoli, Libya

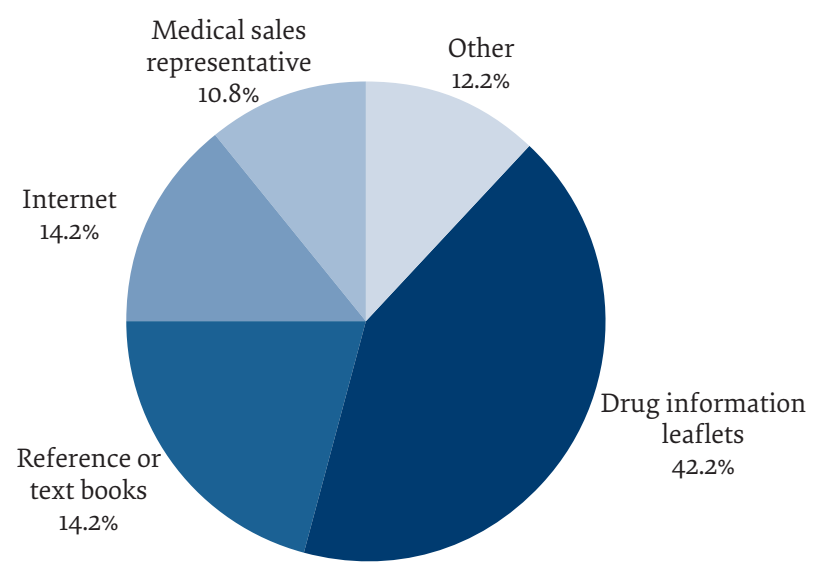


A main limitation of our study was that it was based on a self-reported questionnaire, so personal bias may have affected the results.

Although the knowledge of pharmacists about adverse drug reactions and pharmacovigilance is limited, most of the participants believed that reporting adverse drug reactions was crucial to ensure patient safety and health. Regulators, policy-makers and health care professionals need to reinforce the importance of reporting adverse drug reactions, and pharmacovigilance policies are required in the Libyan health care system. In the first instance, educational and training programmes should be introduced for practising pharmacists to increase their knowledge of and improve attitude toward pharmacovigilance and reporting of adverse drug reactions.

\section{Acknowledgement}

We thank all the pharmacists who took part in this study.

Funding: None.

Competing interests: None declared.

\section{Connaissances, attitudes et pratiques des pharmaciens en matière de pharmacovigilance en Libye}

\section{Résumé}

Contexte : Le concept de pharmacovigilance n'est pas bien connu en Libye et sa pratique en est encore aux premiers stades.

Objectifs : La présente étude visait à déterminer les connaissances, les attitudes et les pratiques des pharmaciens à Tripoli (Libye) en matière de pharmacovigilance et de notification des effets indésirables des médicaments.

Méthodes : Une étude transversale a été menée entre octobre 2019 et février 2020 auprès de pharmaciens en activité sélectionnés de manière aléatoire dans des pharmacies de Tripoli. Les participants remplissaient les conditions pour être inclus dans l'étude s'ils possédaient un diplôme en pharmacie d'une université ou d'un institut reconnu(e). Les données ont été recueillies au moyen d'auto-questionnaires validés.

Résultats: Sur 500 pharmaciens sélectionnés, 408 ont répondu au questionnaire. Globalement, les pharmaciens connaissaient mal la pharmacovigilance et les notifications d'effets indésirables des médicaments : seuls 28,9\% définissaient correctement la pharmacovigilance et 14,7 \% connaissaient l'existence d'un centre de pharmacovigilance en Libye. Les attitudes des pharmaciens vis-à-vis de la pharmacovigilance étaient positives : ils étaient $77,2 \%$ à penser qu'il fallait inclure la pharmacovigilance dans le programme de formation en pharmacie et $73,0 \%$ à affirmer qu'ils exerceraient cette pratique s'ils étaient formés. Les pharmaciens dépendaient principalement des feuillets d'information sur les médicaments pour mettre à jour leurs connaissances sur les effets indésirables des médicaments.

Conclusion: En raison du faible niveau de connaissances des pharmaciens en matière de pharmacovigilance et de leur volonté de s'impliquer s'ils sont formés, des programmes de formation devraient être mis en place pour les pharmaciens en exercice afin d'améliorer leurs connaissances et d'encourager leur participation active à la pharmacovigilance. Les responsables de la réglementation doivent insister sur l'importance de notifier les effets indésirables des médicaments et mettre en œuvre des politiques de pharmacovigilance dans le système libyen de soins de santé.

$$
\begin{aligned}
& \text { معلومات الصيادلة واتجاهاتهم ومحارساتهم بشأن التيقظّ الدوائي، ليبيا } \\
& \text { أحمد عطية، أمل بوتو، صفية العربي } \\
& \text { الخالإنة } \\
& \text { الخلفية: مفهوم التيقّظ الدوائي غير معروف جيدًا في ليبيا، ولا تز ال محارسته في مراحلها الأولى. }
\end{aligned}
$$

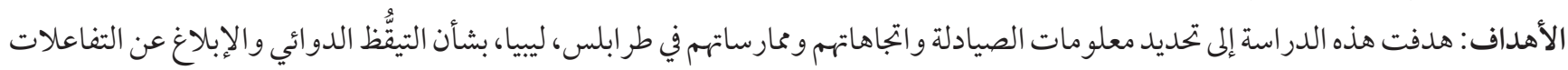

$$
\begin{aligned}
& \text { الدوائية الضارة. }
\end{aligned}
$$

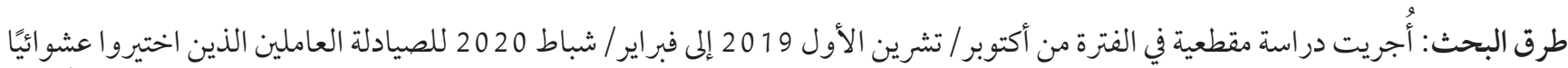

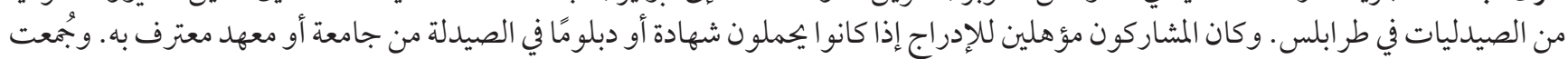

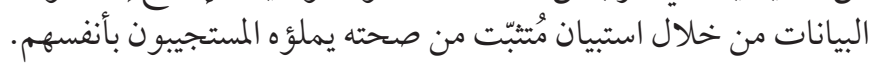




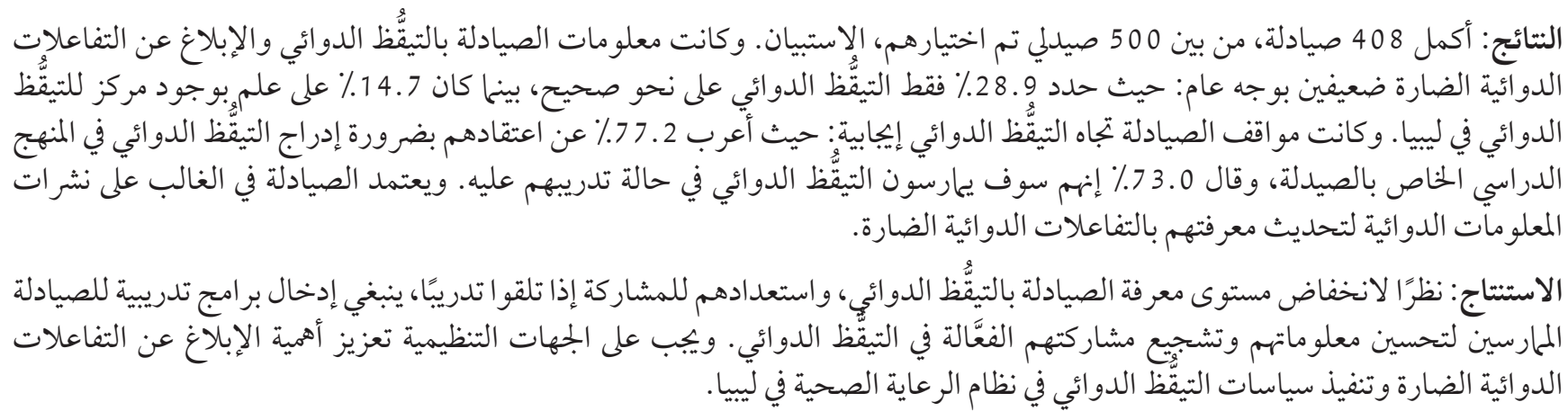

\section{References}

1. Pharmacovigilance: ensuring the safe use of medicines. Geneva: World Health Organization; 2004 (https://apps.who.int/iris/bitstream/handle/10665/68782/WHO_EDM_2004.8.pdf?sequence=1\&isAllowed=y, accessed 4 May 2020).

2. Safety of medicines. A guide to detecting and reporting adverse drug reactions. Why health professionals need to take action. Geneva: World Health Organization; 2002 (http://archives.who.int/tbs/safety/esd_safety.pdf, accessed 11 February 2021).

3. Pirmohamed M, James S, Meakin S, Green C, Scott AK, Walley TJ, et al. Adverse drug reactions as cause of admission to hospital: prospective analysis of 18820 patients. BMJ. 2004;329(7456):15-9. https://doi.org/10.1136/bmj.329.7456.15

4. Lexchin, Joel. Is there still a role for spontaneous reporting of adverse drug reactions? CMAJ. 2006;174(2):191-2. https://doi. org/10.1503/cmaj.050971

5. Adisa R, Omitogun T. Awareness, knowledge, attitude and practice of adverse drug reaction reporting among health workers and patients in selected primary healthcare centers in Ibadan, southwestern Nigeria. BMC Health Serv Res. 2019;19(1):926. https://doi. org/10.1186/s12913-019-4775-9

6. Atia A. Pharmacovigilance in Libya: current status and future trends. Indian J Pharm Pract. 2019;12(4):267-9. https://doi. org/10.5530/ijopp.12.4.56

7. Atia A. Prescribing errors and the need for prescription separation in Libya. Libyan J Med Sci. 2018;2:1-2. https://doi.org/10.4103/ LJMS.LJMS-48-17

8. Taher Y, Faraj S, Samud A, El-Taher F, Sherif F. Pharmacovigilance for pediatric outpatient prescriptions in Tripoli children hospital. Libyan J Med Sci. 2018;2:62-7. https://doi.org/10.4103/LJMS.LJMS-3-18

9. Sekhon M, Gupta A, Sharma N. Evaluation of the knowledge, attitude and the practice of pharmacovigilance among the interns and doctors in a tertiary level care teaching hospital in Northern India. Int J Basic Clin Pharmacol. 2016;5(3):1068-74. http://dx. doi.org/10.18203/2319-2003.ijbcp20161570

10. Dorji C, Tragulpiankit P, Riewpaiboon A, Tobgay T. Knowledge of adverse drug reaction reporting among healthcare professionals in Bhutan: a cross-sectional survey. Drug Saf. 2016;39(12):1239-50. https://doi.org/10.1007/s40264-016-0465-2

11. Alshayban D, Mahmoud MA, Islam MA, Alshammari S, Alsulaiman D. Pharmacovigilance perception and knowledge among pharmacists and interns in Saudi Arabia. Risk Manag Healthc Policy. 2020;13:55-61. https://doi.org/10.2147/RMHP.S241265

12. Albadawi T, Hassan T, Eisa N, Mohamed E, Abdalla S, Sami W. Pharmacovigilance knowledge and attitude of health professionals: a pre-and post-intervention study. J Res Med Dent Sci. 2019;7(5):137-47.

13. Abu Hammour K, El-Dahiyat F, Abu Farha R. Healthcare professional's knowledge and perceptions of pharmacovigilance in a tertiary care teaching hospital in Amman, J Eval Clin Pract. 2016;23:608-13. https://doi.org/10.1111/jep.12683

14. Alsaleh FM, Alzaid SW, Abahussain EA, Bayoud T, Lemay J. Knowledge, attitude and practices of pharmacovigilance and adverse drug reaction reporting among pharmacists working in secondary and tertiary governmental hospitals in Kuwait. Saudi Pharm J. 2017;25(6):830-7. https://doi.org/10.1016/j.jsps.2016.12.004

15. Hajj A, Hallit S, Ramia E, Salameh P, Order of Pharmacists Scientific Committee. Medication Safety Subcommittee. Medication safety knowledge, attitudes and practices among community pharmacists in Lebanon. Curr Med Res Opin. 2018;34(1):149-56. https://doi.org/10.1080/03007995.2017.1361916

16. Wilbur K. Pharmacovigilance in Qatar: a survey of pharmacists. East Mediterr Health J. 2013;19(11):930-5.

17. Vessal G, Mardani Z, Mollai M. Knowledge, attitudes, and perceptions of pharmacists to adverse drug reaction reporting in Iran. Pharm World Sci. 2009;(31):183-7. https://doi.org/10.1007/s11096-008-9276-6 